\title{
Panorama da pesquisa em Jornalismo Ambiental no Brasil: o estado da arte nas dissertações e teses entre 1987 e 2010
}

\section{Ilza Maria Tourinho Girardi}

Doutora; Universidade Federal do Rio Grande do Sul ilza.girardi@ufrgs.br

\section{Eloisa Beling Loose}

Doutoranda; Universidade Federal do Rio Grande do Sul eloisa.loose@gmail.com

\section{Ângela Camana}

Mestre; Universidade Federal do Rio Grande do Sul

angela.camana@ufrgs.br

\section{Resumo}

O artigo tece um panorama da pesquisa sobre Jornalismo Ambiental no Brasil por meio do mapeamento e análise das dissertações e teses sobre o assunto que estão cadastradas no Banco de Teses da Capes no período de 1987 a 2010. A partir da abordagem qualitativa, fez-se uma análise descritiva nos resumos dos trabalhos buscando identificar os temas, referenciais teórico-metodológicos, objetos empíricos, relação com a educação e conceituação de Jornalismo Ambiental; para a elaboração de percentuais e gráficos, fez-se uso da análise quantitativa. O esmiuçamento dos 101 resumos encontrados permitiu que se detectasse em qual região existe maior fomento e interesse na área, o referencial mais utilizado, as lacunas mais recorrentes, dentre outros aspectos que caracterizam os estudos de estado da arte. Além das contribuições sobre como está sendo investigado o Jornalismo Ambiental no País, verificou-se que a compreensão deste conceito não está clara nem entre os próprios pesquisadores do assunto.

\section{Palavras-chave}

Jornalismo Ambiental. Panorama da pesquisa. Estado da arte. 


\section{Introdução}

Este artigo apresenta os resultados finais de uma pesquisa ampla sobre o estado da arte nas dissertações e teses sobre Jornalismo Ambiental no Brasil realizada entre 2011 e 2014 por pesquisadores ligados ao Grupo de Pesquisa Jornalismo Ambiental da Universidade Federal do Rio Grande do Sul (UFRGS)ํ․ O esforço coletivo buscou mapear e sistematizar as informações dos trabalhos finais de pós-graduação que estavam cadastrados no Banco de Teses da Capes, a base de busca escolhida para o recorte desta pesquisa, no período de 1987 a 2010. O Banco de Teses da Capes busca reunir informações acerca de toda a produção acadêmica brasileira, a partir de dados fornecidos pelos próprios programas de pósgraduação reconhecidos no País. A escolha por operar com 24 anos de teses e dissertações justifica-se por limitações do sistema e da própria pesquisa: a plataforma conta com trabalhos recuperados a partir do ano de 1987, enquanto optamos por finalizar as buscas em 2010, ano que antecedeu o início do trabalho aqui encerrado. Sublinhamos que um dos objetivos centrais da pesquisa era checar se os pesquisadores que se debruçam sobre a área fazem distinção entre Jornalismo Ambiental e jornalismo de/sobre meio ambiente, uma discussão bastante presente no âmbito deste grupo de pesquisadores. Assim, de forma geral, agruparam-se todos os trabalhos que relacionavam jornalismo com meio ambiente e, posteriormente, dedicamo-nos à análise dos resumos a partir desta diferenciação proposta.

Em razão dos estudos teóricos de Jornalismo Ambiental ainda serem relativamente novos no Brasil - a primeira disciplina universitária voltada para esta discussão de que se tem conhecimento foi criada em 2004, pela professora Ilza Maria Tourinho Girardi, na UFRGS - e a pesquisa acadêmica ser realizada em função, principalmente, de interesses individuais, percebemos a necessidade de conhecer o que, de fato, já existe em termos de produção sobre o tema. Em uma das primeiras obras nacionais sobre o tema, Bueno (2007) relata que a maioria das pesquisas em comunicação, jornalismo e meio ambiente no país havia sido concluída depois de 2002. Segundo o autor, o desenvolvimento acadêmico desta área é recente, o que pode ser notado pelo número reduzido de investigadores brasileiros que se dedicam ao tema (em 2007, Bueno registrou a existência de dez grupos de pesquisa cadastrados na plataforma do CNPq). Em 2013, durante a realização do II Encontro Nacional de

\footnotetext{
${ }^{1}$ Agradecemos a todos os pesquisadores vinculados ao grupo que, de algum modo, colaboraram para este amplo levantamento: Carine Massierer, Cláudia Herte de Moraes, Eliege Fante, Fabrício Angelo, Gisele Neuls, Patrícia Kolling e Reges Toni Schwaab. Registramos também nosso agradecimento aos bolsistas de Iniciação Científica que participaram de alguma das fases do projeto, assim como às suas instituições de fomento: Giovani de Oliveira (Programa de Iniciação Científica da Universidade Federal do Rio Grande do Sul - BIC/UFRGS), Jamille Almeida da Silva (BIC/UFRGS), Laura Gertz (BIC/UFRGS) e Maria Aparecida Pinto (bolsista voluntária da Universidade Federal de Ouro Preto -UFOP).
} 
Pesquisadores em Jornalismo Ambiental, Aguiar (2013) apresentou alguns dados sobre o perfil da produção brasileira em torno das relações comunicação, mídia e meio ambiente², mostrando que, dos 14 grupos de pesquisa sobre comunicação ambiental encontrados, “[...] a grande maioria institucionalizou-se entre 2006 e 2011, não por acaso coincidindo com a intensificação do debate público mundial sobre a chamada 'crise ecológica' contemporânea." (AGUIAR, 2013, sem paginação).

Mesmo sendo esta uma pesquisa focada na comunicação ambiental - e não no subcampo do jornalismo -, Aguiar (2013, sem paginação) verificou a dominância dos estudos em jornalismo e meio ambiente, apontando ainda que "[...] os grupos que atuam nessa linha de pesquisa são os que possuem as maiores e mais qualificadas equipes, bem como uma produção mais contínua." Além disso, constatou um crescimento no número de dissertações defendidas. Nos cinco anos mais recentes do período analisado (2007-2011) a quantidade de trabalhos na área foi $63 \%$ maior do que a dos cinco anos anteriores. De acordo com a autora, isto "[...] pode ser tanto um sinal de interesse crescente pelo assunto quanto modismo acadêmico" (AGUIAR, 2013, sem paginação).

Deste modo, seja pelo aumento de trabalhos na área, seja pelo domínio que os estudos de jornalismo exercem dentro da comunicação ambiental, justifica-se o interesse na construção de um panorama geral que aponte avanços, caminhos e lacunas a fim de aperfeiçoar este subcampo de investigação. Acreditamos que o aprofundamento dos aspectos teóricos e metodológicos do campo, assim como a expansão do interesse pela área, irão criar condições e novas possibilidades para o ensino mais qualificado dos futuros jornalistas, assim como a realização de práticas mais interessadas com a cidadania e o comprometimento ambiental. Assim, a pesquisa do tipo estado da arte, também chamada de estado de conhecimento, pareceu-nos a opção mais apropriada. Para Ferreira (2002, p. 258), estas investigações de caráter bibliográfico possuem em comum “[...] o desafio de mapear e de discutir uma certa produção acadêmica [...] tentando responder que aspectos e dimensões vêm sendo destacados e privilegiados em diferentes épocas e lugares [...]".

Além de identificarmos as teses e dissertações sobre jornalismo e meio ambiente, no período já citado, buscamos localizar nos seus resumos os temas e enfoques, referenciais teórico-metodológicos, objetos empíricos e a possível relação com a educação. Também lo-

\footnotetext{
${ }^{2}$ Resultados da pesquisa "Geografias da Comunicação Ambiental no Brasil", desenvolvida durante os anos de 2011 e 2012 , que teve como objetivos mapear a produção acadêmica brasileira sobre a relação comunicação/ mídia/ meio ambiente a partir do Banco de Teses da Capes e do Diretório de Grupos de Pesquisa do CNPq, e identificar tendências desses estudos, em termos temáticos, metodológicos, midiáticos, geográficos e institucionais no período de 1988 a 2011 (AGUIAR, 2013).
} 
calizamos as origens geográficas dos trabalhos mapeados e analisamos seu incremento com o passar dos anos. Um dos objetivos iniciais era rastrear a bibliografia mais utilizada nessas pesquisas através de buscas nos trabalhos completos, porém esta tarefa se tornou inviável especialmente pela não disponibilização da versão digital dos trabalhos. Por meio de metodologia descritiva, tabelamos por categorias os diferentes itens a serem examinados e, posteriormente, quantificamos os dados coletados de modo a facilitar a compreensão do todo (foram analisados quais os anos e instituições de maior produção na área, quais os campos do conhecimento mais acionados, quais regiões do País de maior produção, entre outros tópicos). Com isso, combinamos uma abordagem qualitativa e uma quantitativa.

A seguir são expostos, por tópicos, os principais achados da pesquisa com algumas observações teóricas e contributivas. Na parte final, discutimos as implicações destes resultados e apontamos considerações sobre o desenvolvimento da área e das limitações encontradas no decorrer deste processo de pesquisa.

\section{Luzes sobre a pesquisa de Jornalismo Ambiental no Brasil}

Há alguns anos pesquisando a relação entre o Jornalismo e o Meio Ambiente, observávamos trabalhos sobre o assunto defendidos nas mais diversas áreas, os quais analisavam o mesmo objeto por diferentes perspectivas. Esta percepção nos conduziu, pouco a pouco, à pesquisa que ora finalizamos, pois, além de questionarmos a possibilidade de um eixo comum entre a produção encontrada, pensávamos ainda naqueles trabalhos sobre o assunto os quais desconhecíamos. Desse modo, construímos esta pesquisa, centrando esforços no Banco de Teses da Capes ${ }^{3}$.

As buscas por palavras-chave, detalhadas a seguir, foram realizadas entre 2011 e 2012, quando os resultados obtidos foram refinados de forma a manter apenas aqueles que abordassem de forma central o Jornalismo, ainda que o relacionasse à Comunicação, à Educação ou a outra área do conhecimento. São diversas as plataformas que disponibilizam a produção acadêmica, como é o caso das próprias bibliotecas institucionais, mas o Banco de Teses se propõe a atuar como um repositório nacional nesse sentido. No início foram recuperadas informações a partir de 1996, mas logo o período foi expandido até 1987. Desde 2002, o Banco de Teses é atualizado anualmente e hoje conta com mais de 615 mil trabalhos

\footnotetext{
3 O Banco de Teses da Capes é vinculado ao Portal de Periódicos e está disponível no seguinte endereço: <http://bancodeteses.capes.gov.br>. Esta plataforma, fundada em 2002, é alimentada a partir de informações fornecidas pelos próprios Programas de Pós-Graduação (BRASIL, c2006).
} 
cadastrados. Em 2013, a plataforma foi atualizada de forma a ampliar o sistema de buscas, incluindo as opções de pesquisa por palavras-chave, biblioteca, linha de pesquisa, área do conhecimento, programa, agência financiadora e nível.

À época da primeira etapa da pesquisa, entretanto, o Banco de Teses contava apenas com busca por autor, título, instituição e ano da defesa. Desse modo, observa-se a limitação imposta pelo próprio sistema de buscas, que permitiu a obtenção de 101 teses e dissertações acerca do tema do Jornalismo Ambiental e correlatos. 0 mapeamento dos trabalhos centrou-se em todos os campos disponíveis, a partir de uma combinação de categorias organizada pelo grupo de pesquisa que formaram dois eixos: um referente à Comunicação e ao Jornalismo e outro indicativo de temas tidos como ambientais, os quais foram combinados entre si. No primeiro, constavam os termos: Jornalismo, Comunicação, Jornalismo Ambiental, Televisão, Rádio, Internet, Imprensa, Mídia; enquanto o segundo trazia as seguintes palavras: Meio Ambiente, Sustentabilidade, Educação Ambiental, Desenvolvimento Sustentável, Agrotóxico, Amazônia, Transgênicos, Bioma, Ecologia, Natureza, Água, Energia, Consumo, Desmatamento, Agropecuária e Biotecnologia. Os resultados foram obtidos a partir das combinações entre cada palavra do primeiro eixo com todas as do segundo.

Nesta primeira etapa, foram obtidos 202 trabalhos, número que passou por um processo de refinamento, no qual averiguamos os resumos e palavras-chave, percebendo que nem todos poderiam ser compreendidos como objeto de estudo dessa pesquisa, pois grande parte citava os termos buscados, mas não os abordava de maneira central de fato. Após avaliação dessas informações e algumas reflexões do grupo de pesquisadores, realizou-se uma análise quantitativa dos dados e chegou-se a um corpus de 101 trabalhos, sendo oito teses de doutorado, 90 dissertações de mestrado e três trabalhos de pós-graduação profissionalizante.

Pudemos observar, também, um aumento da produção acadêmica sobre Jornalismo Ambiental (em números absolutos) que se dá a partir dos anos 2000. A variação na quantidade de teses e dissertações sobre o tema pode ser observada na Figura 1: 
Figura 1 - Produção sobre Jornalismo Ambiental (1987 - 2010)

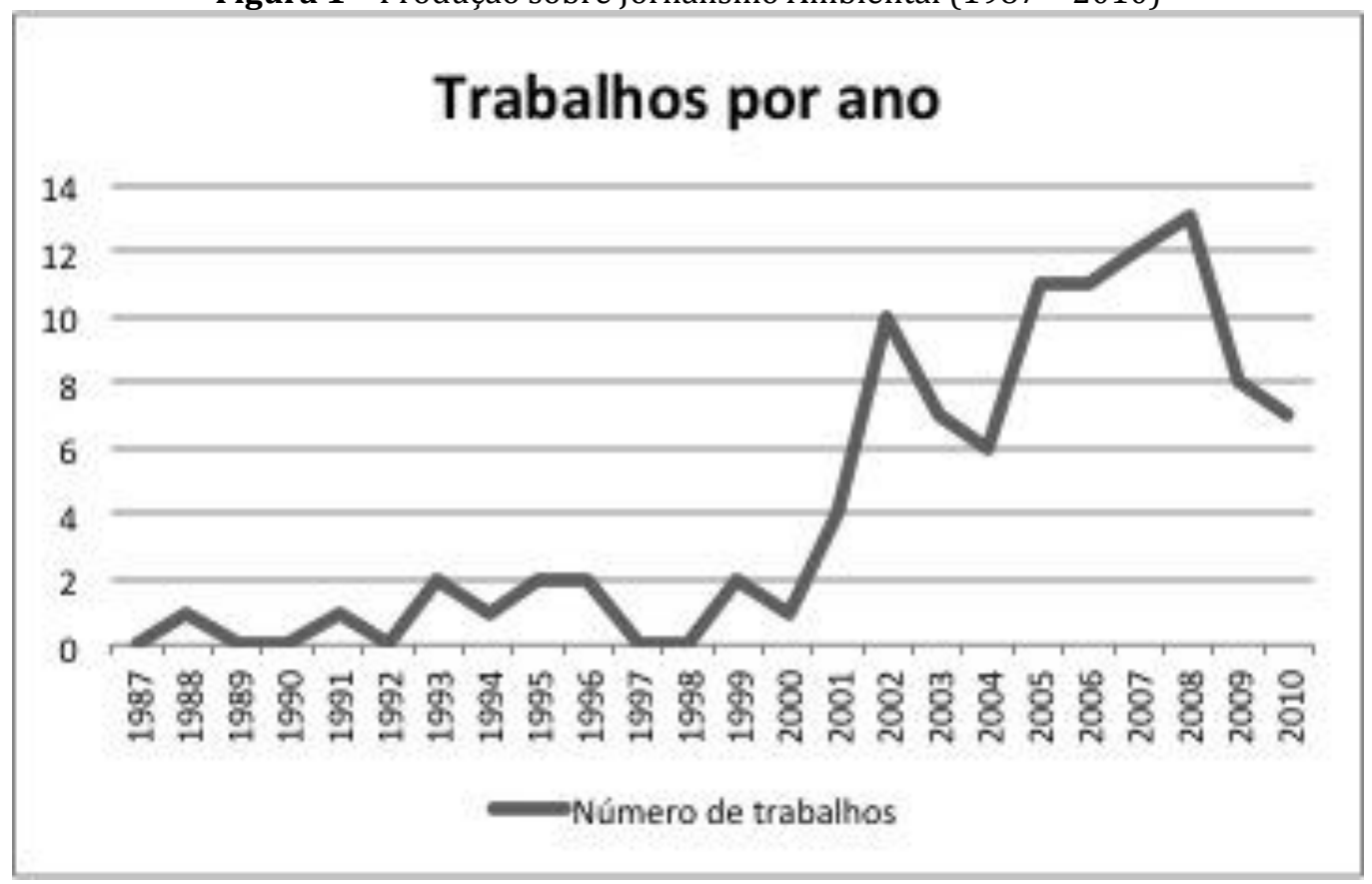

Fonte: As autoras.

O primeiro trabalho sobre o tema - uma dissertação de mestrado defendida na Universidade Metodista de São Paulo - data de 1988. Na década de 1990, a produção permanece estável, com uma ou duas pesquisas apresentadas por ano - embora 1992, 1997 e 1998 não tenham registrado trabalhos. Como o Gráfico 1 demonstra, 2008 é o ano com o maior número de trabalhos (13), seguido por 2007 (12) e 2006 e 2005 (ambos com 11). Apesar da queda na produção em 2009 e 2010, observamos que a pesquisa na área vem em uma crescente, que atribuímos em parte à emergência de eventos e conflitos ambientais, cada vez mais frequentes e mediatizados, e em parte devido ao próprio aumento do acesso a programas de pós-graduação no Brasil.

\subsection{Localização geográfica}

Situar as regiões do país em que mais há registro de dissertações e teses sobre Jornalismo Ambiental nos permite refletir sobre as condições acadêmicas e também de interesse ambiental dos cursos de pós-graduação. Afinal, embora tais trabalhos partam da curiosidade e de trajetórias pessoais dos pós-graduandos, se não há professores que se disponham a orientar essa caminhada e/ou um curso alinhado com esta perspectiva, poucas serão as chances deste projeto inicial não ser modificado. 
Além disso, a manifestação de problemáticas ambientais em estados ou regiões com histórico no movimento ecológico ou com embates desta ordem podem favorecer o desenvolvimento da produção acadêmica. Em agosto de 2007, Bueno confirmou que os grupos de pesquisa registrados no CNPq estavam localizados em universidades localizadas em regiões onde as questões ambientais são mais amplamente debatidas: Amazônia, Centro-Oeste e Sul do Brasil. A pesquisa feita com o material final dos cursos de pós-graduação demonstrou algumas importantes diferenças: dos 100 trabalhos encontrados, a maioria (52 deles) pertence à região Sudeste. A Figura 2 aponta a separação por regiões:

Figura 2 - Distribuição da produção pelas regiões brasileiras

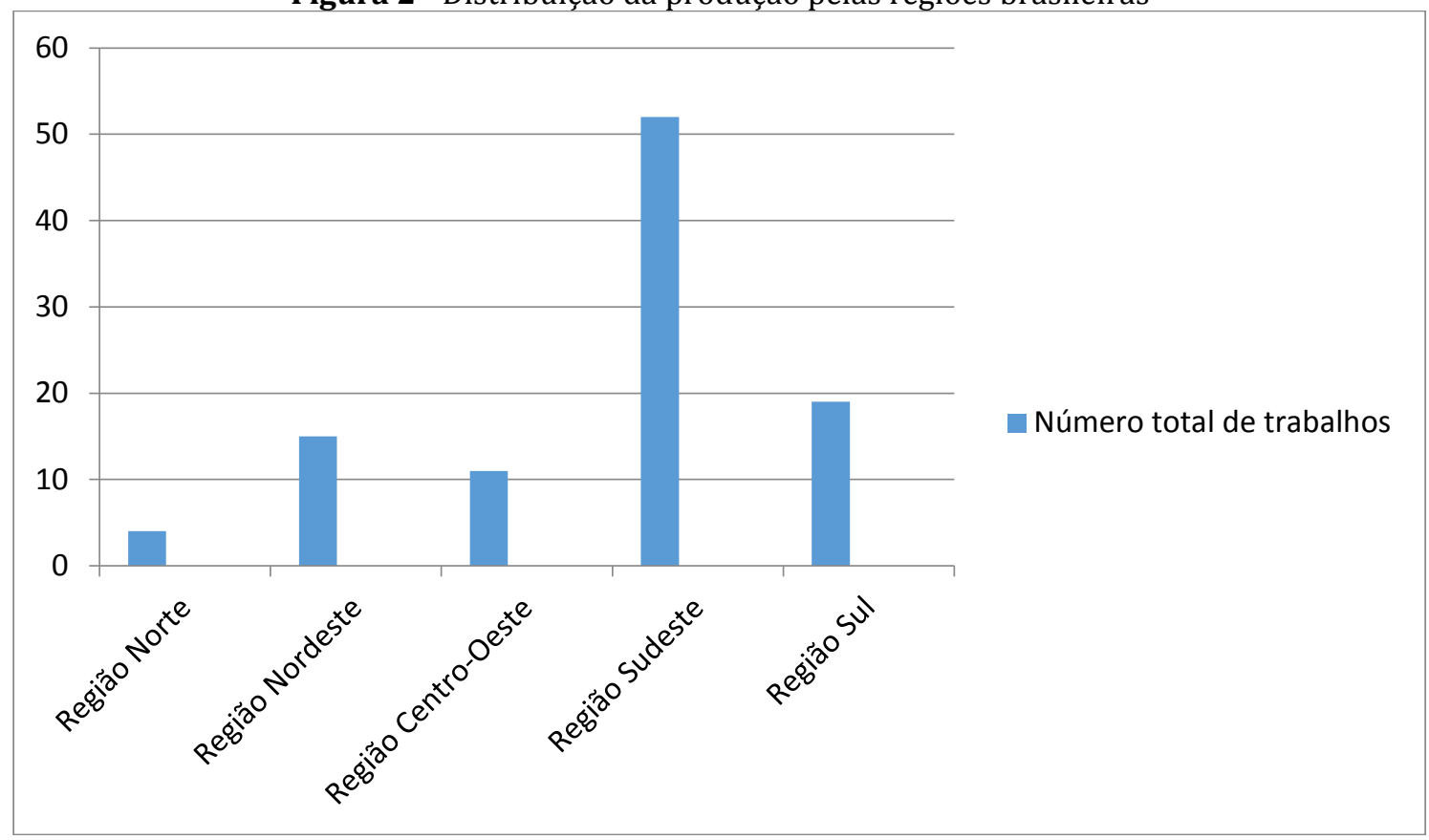

Fonte: As autoras.

Apesar da relação entre grupos de pesquisa e trabalhos finais de pós-graduação não ser automática, é evidente que cursos que possuam grupos de pesquisa na área congreguem mais alunos interessados na temática. Entretanto, talvez por nosso período de análise ser mais abrangente que a pesquisa relatada por Bueno (2007), nossas análises mostraram que a região Sudeste é aquela que mais produz sobre o binômio em análise, o que pode ser justificado tanto pelo número e grau de desenvolvimento dos cursos de comunicação e jornalismo, quanto pela experiência e tradição em produção acadêmica voltada para comunicação científica. Lima et al. (2015, no prelo), ao se deterem sobre dez anos de textos acadêmicos publicados sobre jornalismo e meio ambiente do evento anual da Intercom (organizado pela Sociedade Brasileira de Estudos Interdisciplinares da Comunicação), a partir do núcleo de 
pesquisa que trata da temática ambiental, também constataram que esta região lidera a produção. Para os autores, este resultado está associado à grande concentração de programas de pós-graduação na área da Comunicação, o que, consequentemente, faz com que mais dissertações e teses sejam defendidas em comparação a outras regiões com menor expressão na área acadêmica.

Lima et al. (2015, no prelo) citam o trabalho de Gomes (2001), que fez um estudo do estado da arte do GT Comunicação e Ciência do evento da Intercom de 1992 a 2000, a fim de relacionar as temáticas científicas e ambientais. Gomes (2001), em seu mapeamento, também verificou a predominância de trabalhos na região Sudeste e identificou o Programa de Pós-Graduação em Comunicação da Universidade Metodista do Estado de São Paulo (Umesp), no qual há uma área de concentração em Comunicação Científica e Tecnológica, como um dos fatores que incentiva a produção na região. Lima et al. (2015, no prelo) consideram que mesmo não sendo o Jornalismo Ambiental o foco da análise de Gomes (2001), “[...] vários pesquisadores de comunicação científica deparam-se com assuntos ambientais e acabam escrevendo sobre esta relação.". A constatação se dá porque ambos os temas possuem vários aspectos de convergência.

Em segundo lugar, encontra-se a região Sul, que aí sim coincide com a pesquisa de Bueno (2007). Importante notar que é o estado do Rio Grande do Sul que alavanca essa posição, sendo o segundo com maior produção do Brasil (18 trabalhos), atrás somente de São Paulo (52). Se considerarmos que o primeiro curso de pós-graduação em Comunicação no Rio Grande do Sul começou apenas em 1994, enquanto em São Paulo o primeiro programa já tinha atividades em 1980, entende-se um pouco a disparidade, ao mesmo tempo em que se reconhece a força da área no primeiro estado. Em Santa Catarina foram mapeados seis trabalhos e no Paraná não foram identificados, no período analisado, nenhuma dissertação ou tese relacionada com jornalismo e meio ambiente. Isto pode ser decorrente da demora da inserção de programas de pós-graduação nos cursos de comunicação/jornalismo: na Universidade Estadual de Londrina, as atividades começaram em 2008; na UFPR, em 2011; e na Universidade Estadual de Ponta Grossa, em 2013.

Em terceira posição ficou a região Nordeste, que totalizou 15 trabalhos na área. Em seguida o Centro-Oeste, com 11, e, por fim, o Norte, com apenas quatro. Este último número intriga por ir contra os apontamento de Bueno (2007), de Lima et al. (2015, no prelo) e da própria ideia que os problemas locais, conhecidos, possam interessar como objeto de pesquisa. Ainda que esta região não possua um número expressivo de cursos que possam gerar 
dissertações e teses, o fato de ser um espaço constantemente em disputas por questões ambientais tenderia a colaborar para que a academia também se envolva com esse contexto. Entretanto, o mapeamento feito mostra que esta é a região brasileira mais carente em termos de trabalhos concluídos em programas de pós-graduação.

Os gráficos abaixo (Figuras 3 e 4) sinalizam a quantidade de trabalhos encontrados por estado:

Figura 3 - Distribuição da produção pelos estados brasileiros.

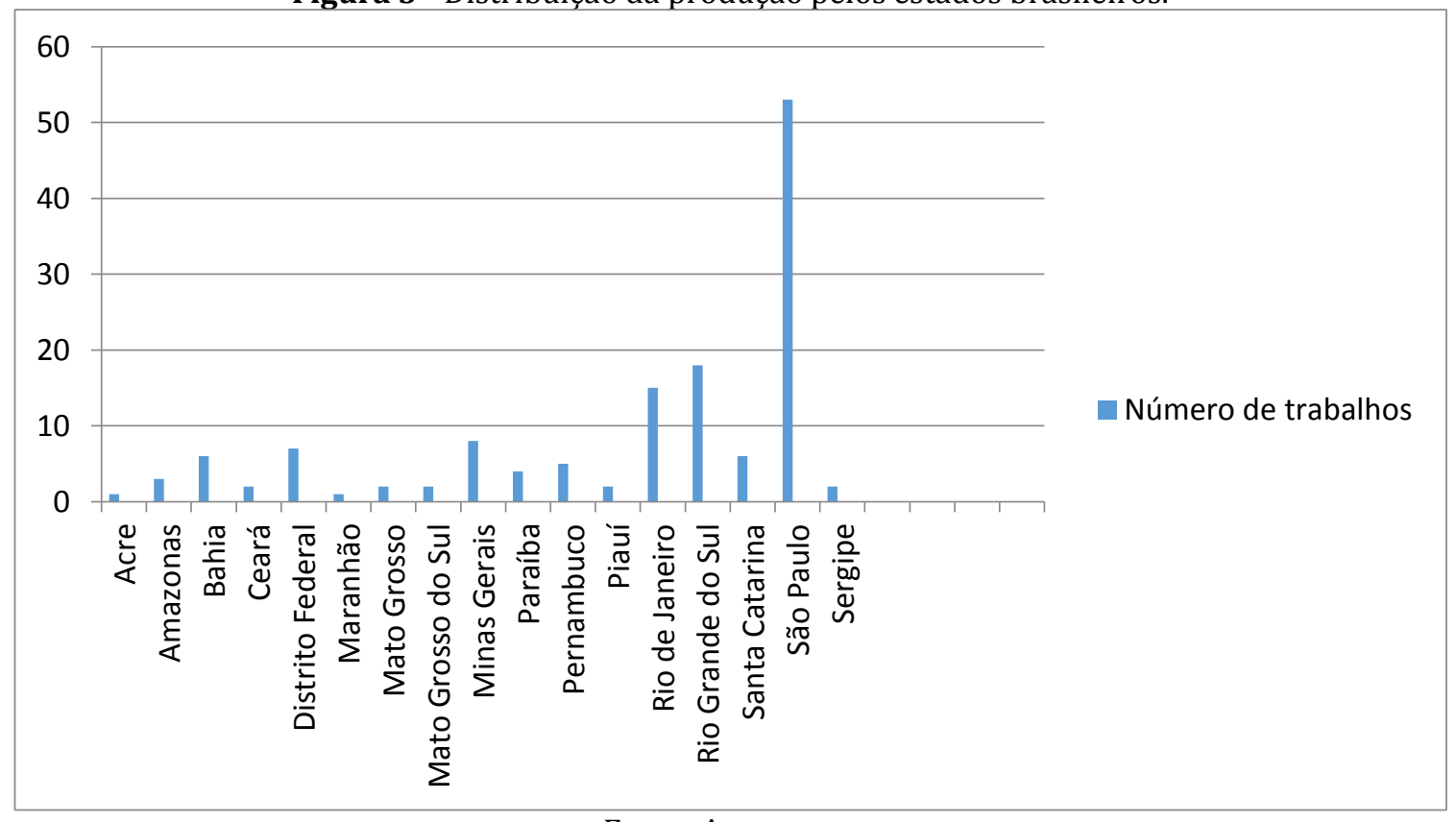

Fonte: As autoras. 
Figura 4 - Visualização da produção pelos estados brasileiros.

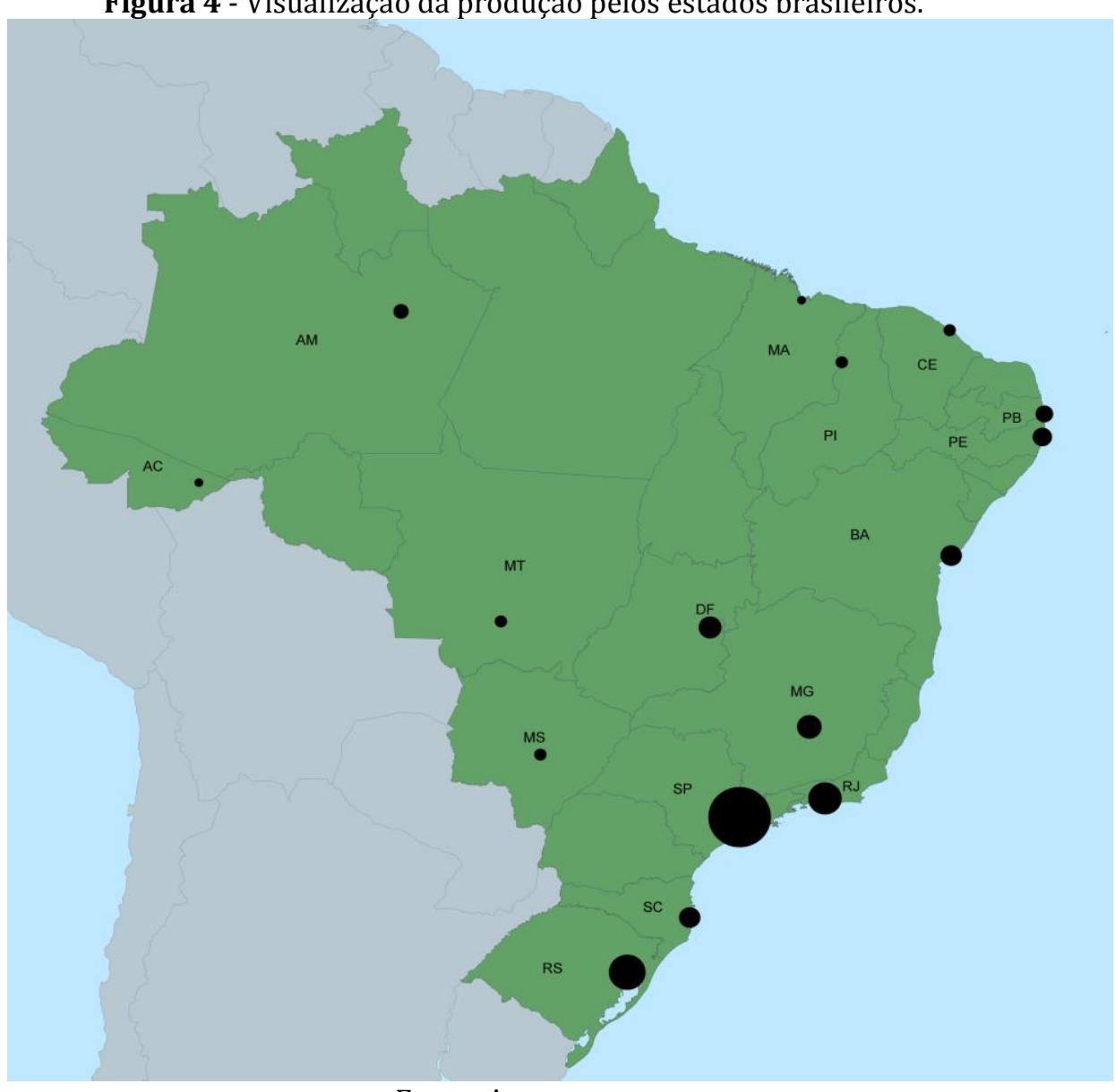

Fonte: As autoras.

Desta forma, a pesquisa constatou que o assunto ainda representa um espaço bastante limitado no campo de estudos de comunicação/jornalismo. Muitos estados nem apresentaram trabalhos com este enfoque e grande parte deles não chega a somar dez produções em um período de 24 anos. As regiões Sul e Sudeste juntas correspondem a 70,2\% de dissertações e teses sobre o tema encontradas, com destaque para os estados de São Paulo, Rio Grande do Sul e Rio de Janeiro.

\subsection{Temas e enfoques}

A análise que se seguiu buscou mapear quais eram os temas e enfoques que mais eram abordados nas dissertações e teses coletadas. Nesse sentido, classificamos, primeiramente, os 101 resumos da amostra final em três grandes grupos: (1) produto jornalístico (que engloba qualquer tipo de análise feita a partir de notícias, reportagens ou outros textos produzidos por jornalistas nos diferentes veículos de comunicação - TV, revistas, jornais, rádio e 
internet), (2) processo jornalístico (relacionado aos estudos das rotinas produtivas, ao relacionamento entre fontes e jornalistas, às percepções dos produtores da notícia, etc.) e (3) recepção (atrelada ao que diferentes públicos percebem a partir do material jornalístico). Pontuamos que, em alguns casos, as pesquisas combinavam elementos, como recepção e produto ou processo e produto, por exemplo.

O gráfico abaixo (Figura 5) evidencia a predominância dos enfoques sobre produtos jornalísticos em busca do viés ambiental ou mesmo de caráter ambiental com o sentido de avaliá-lo segundo os pressupostos que a teoria apresenta.

Figura 5 - Enfoques predominantes.

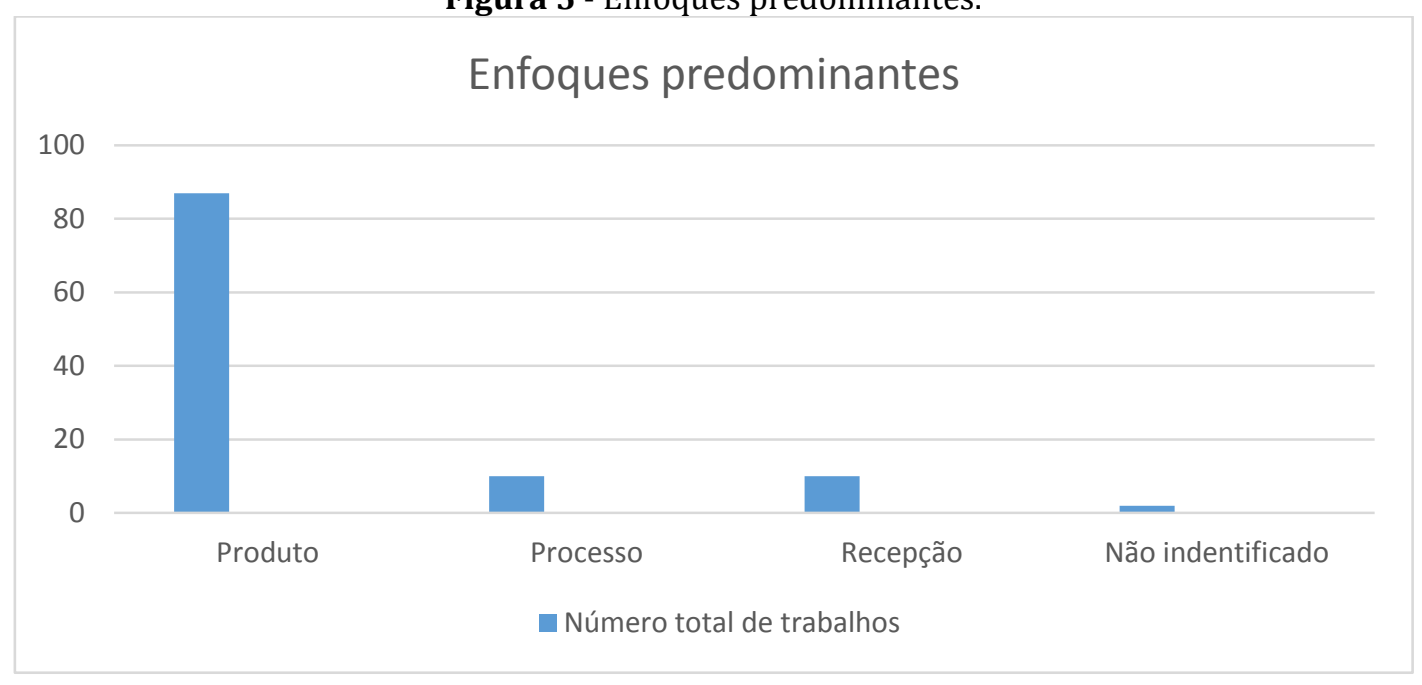

Fonte: As autoras.

Quando nos debruçamos sobre os conteúdos que estão analisados nestes produtos, verificamos que há um amplo leque de assuntos: desde questões amplas, como sustentabilidade, até recortes mais específicos, como Pantanal, dia do meio ambiente, indústria madeireira ou energia nuclear. No gráfico seguinte (Figura 6) apresentam-se as temáticas mais recorrentes: 
Figura 6 - Temáticas mais recorrentes

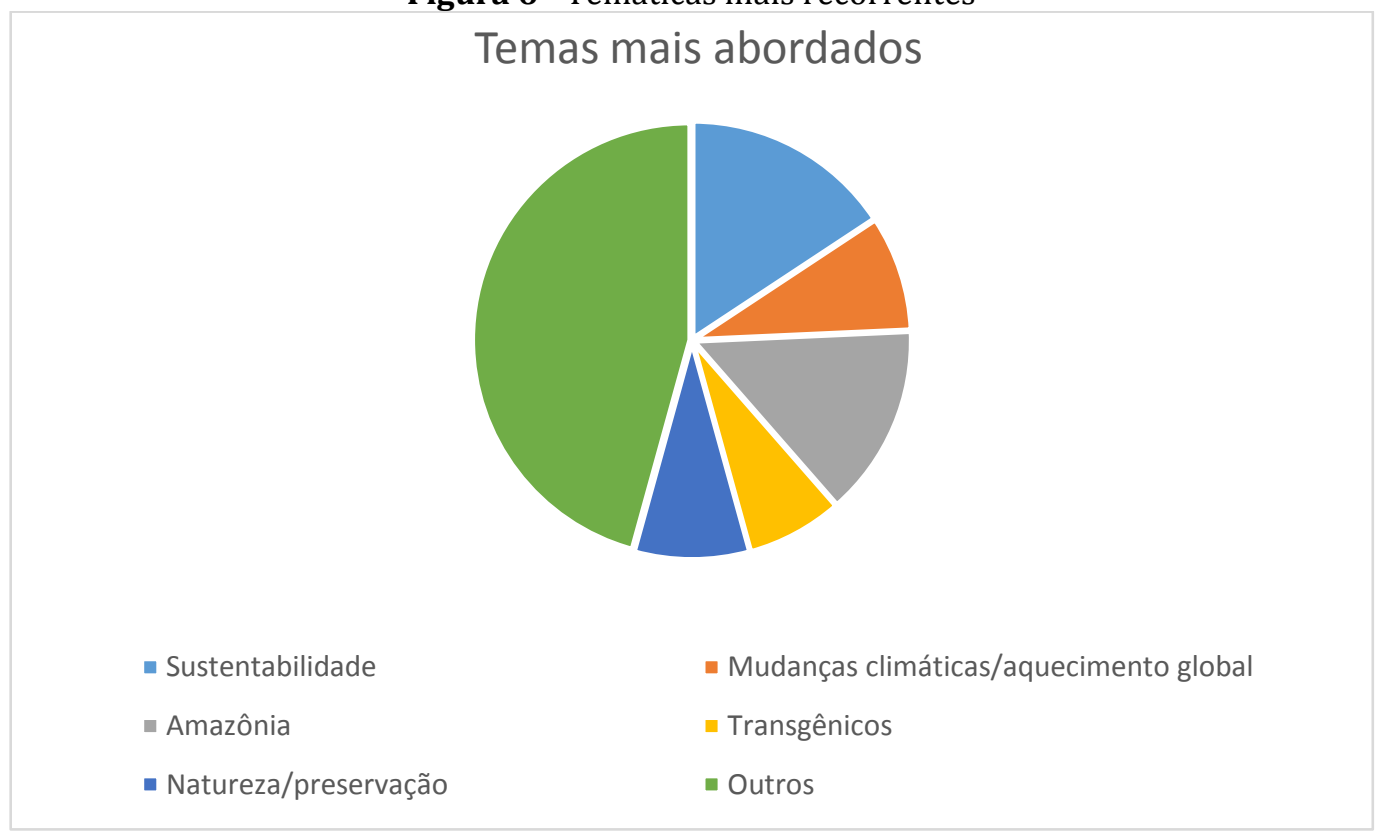

Fonte: As autoras.

Esclarecemos que na categoria "Outros" foram somados todos os assuntos que não se repetiram mais de quatro vezes. Poluição, desmatamento, biodiversidade, acidentes ambientais, problemas urbanos, crise energética, questão nuclear, pesca e políticas públicas foram alvo de estudos mais de uma vez. Já desertificação, carnicicultura, água, Pantanal, indústria madeireira, reservas florestais, dunas costeiras, agrotóxicos, resíduos industriais, questão indígena e agropecuária foram temas analisados por apenas um dos trabalhos da amostra. Além disso, há trabalhos que se detém a analisar a questão ambiental, em um sentido amplo, não tratando de temáticas específicas nos resumos.

Outra análise feita buscou investigar quantas vezes os resumos das pesquisas apresentavam a expressão "educação ambiental". Há uma forte relação entre a função social do jornalismo e a questão da alfabetização científica, intrínseca ao jornalismo que lida com assuntos complexos, como o de meio ambiente, com a perspectiva da educação ambiental informal. Aguiar (2013, sem paginação) ratifica este olhar, afirmando que até os anos 1970, “[...] educação e comunicação ambiental eram vistas como dois lados da mesma moeda [...]”, perspectiva ainda hoje encontrada em muitas pesquisas empíricas no Brasil.

O rastreamento realizado constatou que 19\% dos resumos faz menção a esta expressão. Esta porcentagem aumenta ainda mais quando se mapeia a noção de cidadania e a contribuição da mídia na conscientização dos problemas ambientais, totalizando 30\% dos re- 
sumos. Alguns exemplos dessa próxima relação entre Jornalismo Ambiental e educação podem ser vistos nos trechos a seguir:

O estudo verifica a importância dessas informações veiculadas pelos dois jornais escolhidos como objeto desse estudo, para a formação da consciência ambiental de seus leitores. (NOGUEIRA, 2008).

0 objetivo deste trabalho é analisar como o jornal impresso tem respondido à demanda de que os meios de comunicação sejam instrumentos de Educação Ambiental. (RABELO, 1996).

O objetivo geral é analisar as inter-relações entre o jornalismo opinativo e educação ambiental no discurso do editorial da publicação mencionada. (MAFALDO, 2008).

Esta dissertação busca estabelecer relações entre jornalismo, educação e meio ambiente, investigando através de estudo de recepção os possíveis aspectos educativos do noticiário sobre a crise ambiental veiculado pelos meios de comunicação. (LÜCKMAN, 2007).

Em virtude da responsabilidade social que lhe é inerente, o jornalismo deve voltar-se para a educação ambiental permanente. (CAMPOS, 2006).

Estes achados ressaltam a função pedagógica do jornalismo, de forma geral, e do Jornalismo Ambiental, especificamente. Percebemos que mais que identificar como as temáticas ambientais estão sendo reportadas para os produtos jornalísticos, há uma constante preocupação em relacionar esta cobertura com o papel social da imprensa, descrito, dentre outras formas, como "agente de transformação da realidade" (TEIXEIRA, 2008) e "[...] fundamental para a formação de uma opinião crítica e complexa da questão ambiental e de suas possíveis soluções." (CAMPÊLLO, 2007).

\subsection{Referencial teórico-metodológico}

Muitos dos resumos analisados não apresentavam a metodologia empregada ou o faziam de forma genérica (abordagem quantitativa ou qualitativa). De todo modo, em consonância com o enfoque mais pesquisado, o produto jornalístico, os referenciais teóricometodológicos mais citados estão vinculados à perspectiva da análise do discurso (em suas diferentes vertentes), mencionado 20 vezes, e da análise de conteúdo, 25 vezes. A aplicação e análise de entrevistas e questionários - realizada com públicos, jornalistas e fontes de informação - foi identificada nos resumos 12 vezes. Lembramos que muitos trabalhos apresentam combinações, sendo que estas recorrências não podem ser diretamente relacionadas com o número total de resumos. 
Além disso, foram encontrados como aportes téorico-metodológicos a semiologia, os estudos de recepção, a hermenêutica de profundidade, a fenomenologia, a escrita historiográfica, o método comparativo, os estudos de caso, o método etnográfico (dentro do qual se verificaram procedimentos como a observação participante) e o newsmaking. Em relação aos procedimentos analíticos, muitos resumos empregam análises descritivas, sem explicitar os autores ou abordagens das quais fazem uso para analisar seu corpus empírico.

Apontamos como um dos grandes problemas detectados no processo desta pesquisa, a ausência de informações nos resumos das teses e dissertações, o que acabou por inviabilizar que nossos resultados pudessem revelar um quadro mais preciso do estado de arte das pesquisas brasileiras nesta área. A opção pela análise dos resumos e não dos trabalhos completos, seja em razão do acesso, seja em razão do tempo disponível para a pesquisa, traz ainda outras limitações, reconhecidas pelas autoras da referida pesquisa.

\subsection{Objetos empíricos}

Considerando que os olhares dos pesquisadores sobre jornalismo e meio ambiente estão majoritariamente centrados em produtos (sobretudo notícias), não é de se impressionar que mais da metade dos resumos se dediquem a análise de jornais. A cobertura da mídia impressa (jornais e revistas) representa $78 \%$ da amostra. Vejamos o gráfico:

Figura 7 - Objetos empíricos.

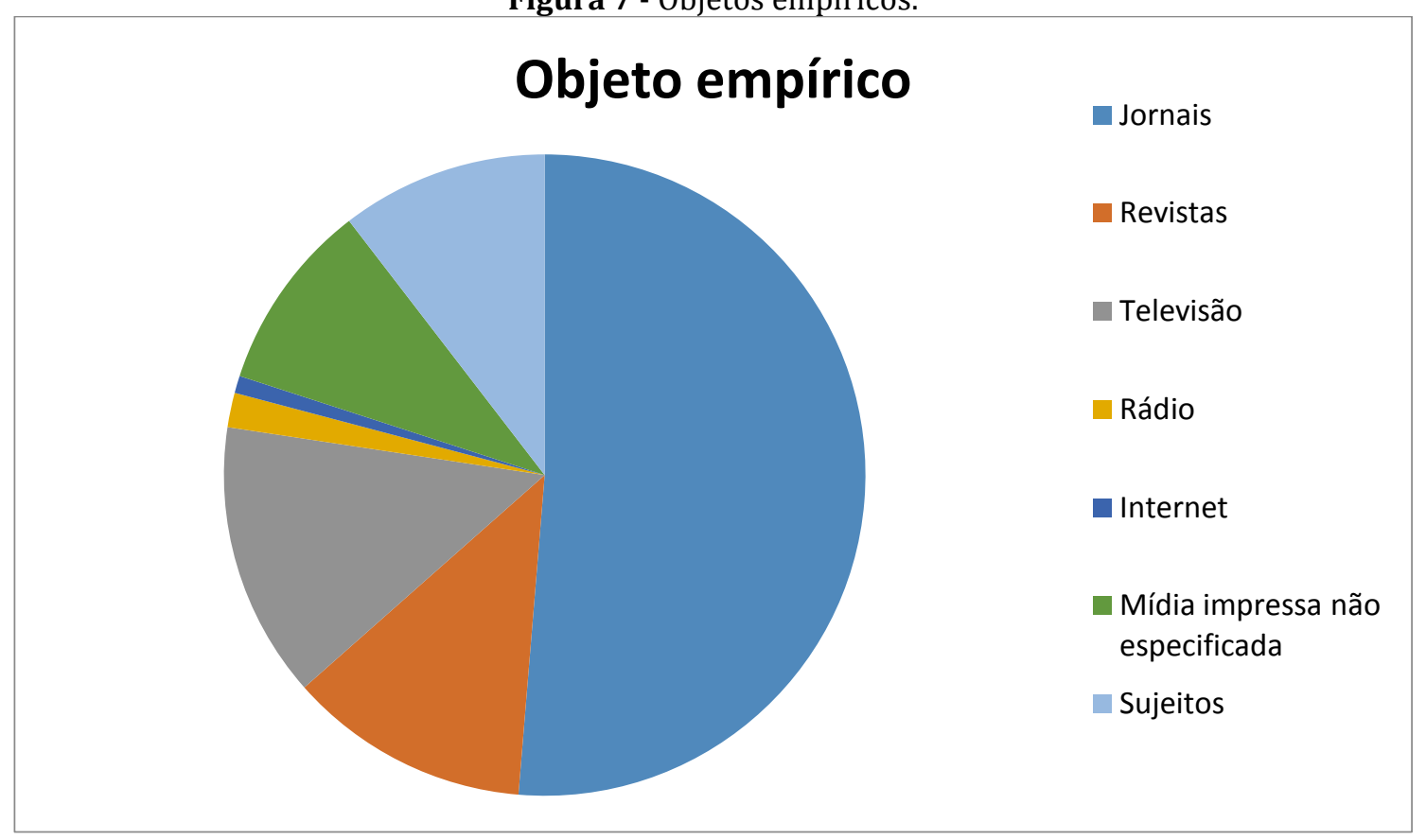

Fonte: As autoras. 
Cabe esclarecermos que alguns resumos se propõem a analisar revistas e jornais, por exemplo, o que faz o número de objetos empíricos aumentar se pensarmos no número total de resumos. Os 78,2\% de cobertura de mídia impressa equivalem à soma de revistas (14 trabalhos), jornais (59) e mídia impressa não especificada - quando os autores não mencionam o título a ser examinado - (11), subtraídas as repetições (resumos que analisam revistas e jornais foram contados apenas uma vez). Entre impressos locais e nacionais, especializados ou de informação geral, notamos que a revista Veja, com oito referências, e o jornal Folha de São Paulo, com 18, receberam mais atenção dos pesquisadores no período investigado. Isso se explica pelo alcance nacional dos dois veículos e também por publicarem com frequência notícias relacionadas com o meio ambiente.

Em seguida, os programas e conteúdos de televisão foram os objetos mais frequentes, com 16 menções. Aqui chama atenção o programa Globo Repórter, da Rede Globo, que foi analisado em cinco trabalhos diferentes.

Os sujeitos não costumam ser foco exclusivo das pesquisas, sendo geralmente entrevistados para compor aspectos que não são possíveis de conseguir por meio da análise dos produtos. A internet, que foi citada em apenas um resumo, também foi investigada com objetivos secundários (a ênfase deste trabalho era um programa de TV, que tinha página na internet). Talvez essa ausência de estudos atrelados aos meios digitais tenha a ver com o recorte do período, já que trabalhos defendidos até 2010 precisariam ser iniciados em 2008 (no caso das dissertações) e 2006 (no caso das teses), momentos em que o jornalismo online ainda não tinha a força que apresenta hoje.

Em relação ao rádio, apenas dois resumos estavam voltados para sua prática, algo que se reflete também nos estudos de jornalismo no sentido geral.

\subsection{Conceituação de Jornalismo Ambiental}

Com a realização desta pesquisa desejávamos também verificar a compreensão do termo Jornalismo Ambiental nos 101 trabalhos selecionados. 0 alcance do objetivo ficou comprometido porque os resumos muitas vezes não apresentam as informações completas e nem sempre conseguimos ter acesso às dissertações e teses completas. 0 termo pode aparecer no resumo, mas sem os elementos necessários que nos permitam chegar a um conceito mais elaborado. No entanto, nesses casos, computamos como trabalhos que têm a compreensão sobre o que é Jornalismo Ambiental. Assim identificamos 11 pesquisas que empregam o conceito, 23 nas quais o conceito não fica claro (dentre esses, um utiliza o termo 
no título, mas não o conceitua e nem o emprega no resumo) e 67 que não conceituam o Jornalismo Ambiental.

Já tendo observado a multiplicidade, e mesmo ambiguidade, das abordagens na área, viemos propondo duas categorias diferentes: jornalismo de/sobre meio ambiente e Jornalismo Ambiental (GIRARDI et al., 2013a; 2013b). O jornalismo sobre/de meio ambiente é aquele que aborda os temas ambientais de forma superficial e imparcial, como se tal imparcialidade fosse possível (GIRARDI et al., 2013a). A própria noção de ambiente neste caso é bastante restrita, pois ancora-se na crença que separa sociedade e natureza, sendo a segunda o objeto de tal prática jornalística. Matérias que apresentam esse olhar são muito frequentes. Além de terem um viés econômico e político (a serviço dos interesses econômicos de curto prazo), não mostram as conexões dos temas abordados com a cultura e com os aspectos ambientais.

Já o Jornalismo Ambiental, em nossa perspectiva, exige o cumprimento dos seguintes requisitos: apresentar uma visão sistêmica dos fatos; reconhecer a complexidade dos eventos ambientais que não podem ser reduzidos e formatos simplistas; contemplar a diversidade dos saberes e não ficar refém de fontes oficiais (que são importantes, mas não são as únicas); defender a biodiversidade e a vida em sua plenitude, o que significa deixar de ser imparcial; e assumir seu papel educativo, cidadão e transformador (GIRARDI et al., 2013a). Em resumo:

\begin{abstract}
O jornalismo ambiental, partindo de um tema específico (mas transversal), visa ser transformador, mobilizador e promotor de debate por meio de informações qualificadas e em prol de uma sustentabilidade plena. Para sua concretização é necessário buscar respaldo em olhares mais abrangentes, que possibilitem ver as conexões, superar a fragmentação reiterada. Fundem-se, desta forma, a natureza do jornalismo especializado com as demandas socioambientais que acabam por compor o horizonte de reflexão dos paradigmas emergentes. (GIRARDI et al., 2012, p. 148).
\end{abstract}

Esta abordagem, que revela uma postura profissional e pessoal, é construída em diálogo com diversos pensadores. Gelós (2008) coloca em pauta a própria definição moderna de ambiente, que não leva em consideração a teia de relações entre sujeitos e natureza, sendo limitada por si mesma. Para este autor, o Jornalismo Ambiental é ferramenta indispensável para a superação de tal dicotomia, pois promove o empoderamento de seus interlocutores: “[...] deve ser um promotor de cidadania, entendendo por cidadania a consciência e o 
exercício do direito de estar bem informado, e participar das decisões que afetam as condições de nossas vidas." (GELÓS, 2008, p. 72, tradução nossa4").

Deste modo, evidenciamos que o Jornalismo Ambiental não é permeado por imperativos éticos de isenção, mas - ao contrário - é comprometido. Ao desvelar a complexidade das tramas que aborda e perceber as intraconexões entre os seres (sejam estes humanos ou não humanos), o Jornalismo Ambiental se constitui como revolucionário. Também deste modo pensa Belmonte (2015, p. 70), quando assinala o potencial transformador dessa prática5:

Este [o Jornalismo Ambiental], por definição, sempre vai questionar o sistema capitalista apontando caminhos para a sua reforma estrutural (redução do consumo, qualidade do crescimento) e/ou para a sua possível superação (novas formas de organização social).

Observamos nesta pesquisa que tais noções sobre Jornalismo Ambiental não são muito bem compreendidas entre os próprios pesquisadores, que tecem críticas ao Jornalismo Ambiental, quando estas deveriam ser dirigidas ao jornalismo sobre/de meio ambiente, que, como já dito, é uma forma de tratar o tema ambiental sem o envolvimento, que significa uma atitude interna do jornalista pela defesa da vida.

Em relação aos 11 trabalhos que conceituam Jornalismo Ambiental, oito compreendem seu significado e é possível perceber que seus autores assumem a perspectiva crítica do jornalismo por creditarem a ele um papel educativo importante capaz de tocar/sensibilizar os leitores/ouvintes/telespectadores/internautas sobre os problemas socioambientais. Este é um aspecto importante no processo de conscientização necessário atualmente devido à gravidade dos problemas ambientais. Nesses resumos encontramos os termos "concepção crítica", "interconexão", "interdependência”, "diferentes fontes/vozes", "pensamento complexo", "visão sistêmica”, "mobilização", "conscientização", "contexto", "participante justo do jornalismo cívico", "confronto de opiniões”, que marcam a compreensão do alcance do Jornalismo Ambiental. Expressões como "fragmentariamente" e "questões ambientais de forma distorcida e insuficiente" identificam se com a crítica à cobertura ambiental a partir dos pressupostos do Jornalismo Ambiental.

Os trechos dos resumos apresentados a seguir ilustram aspectos importantes sobre como o Jornalismo Ambiental é conceituado pelos pesquisadores:

\footnotetext{
${ }^{4}$ No original: "No se debe olvidar que, como agente social que es, el PERIODISMO AMBIENTAL debe ser un generador de ciudadanía, entendendo por ciudadanía la conciencia y el ejercicio del derecho de estar bien informado, y a participar en las decisions que afectan las condicionesde nuestras vidas.".

${ }^{5}$ Para o autor, são três as abordagens possíveis ao Jornalismo: de mercado, reformista e revolucionária. Estas perspectivas, entretanto, por vezes opõem-se e noutras ocasiões travam alianças.
} 
Para isso os pressupostos do jornalismo ambiental estão fundamentados numa concepção crítica do jornalismo praticado pelos jornais Diário do Amazonas e a Crítica. (NOGUEIRA, 2008).

A dissertação busca discutir o papel do jornalista ambiental, na condição de participante justo do jornalismo cívico, na explicitação do conflito entre o desenvolvimento econômico e a preservação do meio ambiente." (ROCHA, 2004).

[...] a complexidade e a visão sistêmica, tão necessárias à compreensão das relações que envolvem meio ambiente, constituem um dos grandes desafios ao Jornalismo Ambiental nas práticas diárias. Isto somente será possível quando as notícias deixarem de ser apresentadas fragmentariamente e passarem a ser contextualizadas, possibilitando que outras fontes tenham voz e vez. 0 jornalismo diário precisa então ser visto com um novo olhar, a partir da perspectiva cívica e pública, que contribua para a conscientização dos seres humanos à preservação do planeta." (MASSIERER, 2007).

O jornalista como ator social e mediador de sentidos, não pode estar ausente do debate ambiental. Ter uma visão de mundo sistêmica é a única forma de conseguir produzir reportagens impregnadas de transversalidade, caminho que torna possível o oferecimento ao leitor de toda a complexidade contemporânea. (GERAQUE, 2006).

Nesse conjunto de trabalhos identificamos três que revelam que os autores não distinguem Jornalismo Ambiental de jornalismo de/sobre meio ambiente. As críticas contidas nos resumos são procedentes, mas são dirigidas equivocadamente ao Jornalismo Ambiental, justamente porque elas são formuladas a partir do olhar do Jornalismo Ambiental, que como já mencionado neste artigo, é comprometido com a causa ambiental.

Partindo da análise de trabalhos acadêmicos que apresentam críticas ao chamado jornalismo ambiental, desenvolvemos um estudo empírico com o objetivo de verificar como as notícias sobre meio ambiente são recebidas pelo público. (LÜCKMAN, 2007).

O espaço geográfico, porém, é interpretado principalmente a partir da ótica dos atores hegemônicos ou do discurso da ciência. Sobra pouca ou nenhuma possibilidade para que outros atores sociais produzam suas próprias interpretações sobre os conflitos que se estabelecem nos diferentes lugares onde os discursos jornalísticos são formulados. (ABREU, 2004).

[...] o jornalismo ambiental, tal como praticado hoje, não conduz à reflexão, não estimula a visão crítica, não explica as causas e consequências das informações e não abre espaço para a livre manifestação do receptor, atado que está a compromissos incompatíveis com a biofilia, isto é, com a vida e com a paz. (CAMPOS, 2006).

A análise nos permitiu verificar que os respectivos autores, mesmo não tendo o objetivo de desenvolver a sua pesquisa à luz do que consideramos Jornalismo Ambiental, estão sempre atentos à função social do jornalismo. 


\section{Discussão e considerações finais}

Recordamos que nosso grande propósito ao realizar este estudo era tentar demarcar a singularidade do Jornalismo Ambiental, mostrando as conexões teóricas que envolvem o conceito e apontando uma orientação para pesquisadores que têm o Jornalismo Ambiental como objeto de investigação, bem como aos professores que contribuem com a formação dos novos profissionais e aos repórteres especializados em meio ambiente. Por isso, acreditamos que a sintonia dos pesquisadores em relação aos paradigmas teóricos que nos iluminaram para compreender o que é e o que não é Jornalismo Ambiental é fundamental para que nossas pesquisas cumpram o papel que cabe à investigação acadêmica: apontar os problemas da cobertura ambiental com o intuito de cuidar para que o jornalismo não se afaste de sua função social. Verificamos que ainda são poucos os estudos que distinguem Jornalismo Ambiental de jornalismo de/sobre meio ambiente, revelando desconhecimento sobre discussões conceituais e de ordem epistemológica já bastante discutidas em eventos e artigos científicos.

Com a pesquisa percebemos pelo menos duas lacunas. Uma de natureza metodológica: os resumos não se mostraram adequados para um estudo mais detalhado, uma vez que não apontam todos os elementos centrais ao trabalho (paradigma teórico, objeto, tema, método), o que tornou difícil a identificação de certos quesitos analisados; e outra relacionada à disposição geográfica das pesquisas: a produção permanece centrada no Sudeste, o que, por vezes, pode impedir estudos sobre realidades localizadas (Centro-Oeste, por exemplo). Observamos que há uma concentração de pesquisadores que investigaram temas e veículos de sua região em cursos localizados nas regiões Sudeste ou Sul. Nesse sentido, percebe-se a necessidade de expandir a preocupação com as relações entre jornalismo e meio ambiente para as demais regiões brasileiras, de modo a fomentar um interesse nacional na qualificação da cobertura ambiental, transversal por natureza.

Destacamos ainda duas ordens de limitações, que nos impedem de chegar a conclusões mais ricas: (1) temporal - sabemos que existem trabalhos defendidos após 2010, mas o recorte de tempo foi necessário metodologicamente (pois permitiu desenvolver a pesquisa em etapas, sendo o mapeamento por palavras-chave a primeira delas); (2) estrutural - o banco de teses estava em sua versão antiga, o que pode ter gerado falhas na inclusão de trabalhos, que podem não ser o número total em razão do próprio descuido dos programas de pós-graduação no fornecimento de dados de sua produção. 
Os resultados obtidos nos alertam para a necessidade de mais estudos relativos aos veículos televisão e rádio, já que são os que têm as maiores audiências no País (BRASIL, 2014). Infere-se que essa pouca presença de trabalhos se deva à dificuldade para a reunião do corpus, aspecto que precisa ser superado. A internet, por sua vez, está em terceiro lugar na audiência dos brasileiros (BRASIL, 2014) e nossa pesquisa também constatou uma "quase ausência". Sinaliza-se para que outros objetos empíricos, diferentes dos impressos, fomentem debates a respeito do Jornalismo Ambiental.

Da mesma forma, novos enfoques teóricos-metodológicos são bem-vindos. Análises sob o olhar da produção e da circulação continuam escassas. Sugerimos o incremento nos estudos de recepção, que permanecem afastados das temáticas ambientais, poderão trazer respostas a muitas dúvidas que pairam sobre a relação da informação com a mudança de comportamento do receptor no sentido de adotar atitudes mais ecologicamente corretas. É preciso conhecer mais sobre o processo de mudança de comportamento do cidadão a partir de uma perspectiva mais sustentável. Como deve ser a informação para afetar o receptor? Qual o papel das imagens? O medo que a reportagem pode gerar é positivo? Ou gera uma reação contrária?

A pesquisa nos proporcionou a construção de um cenário amplo sobre o que é investigado e esperamos que de 2010 em diante o número de pesquisadores interessados em Jornalismo Ambiental tenha aumentado, na medida em que as matérias sobre meio ambiente estão cada vez mais presentes nos meios de comunicação, tendo em vista os muitos desafios ambientais que, dia a dia, são postos. 0 acirramento da crise ambiental, que exige medidas urgentes para a sua solução, necessita da pressão dos cidadãos via movimentos socioambientais. Nesse processo, destaca-se o papel da imprensa como fonte de informação gabaritada e capaz de subsidiar as ações da cidadania na luta pela melhoria da qualidade de vida.

Assim, o Jornalismo Ambiental assume uma função semelhante a da educação ambiental, justamente por produzir informações que interpretam os problemas, produzem previsões e alertam para o que poderá surgir no futuro, caso não sejam tomadas as decisões corretas, além de sugerirem soluções. E aqui está a centralidade do Jornalismo Ambiental, que ao assumir sua perspectiva revolucionária, tem potencial para ajudar na superação desse cenário ambiental cada vez mais sombrio. Diante disso, a pesquisa acadêmica não pode se omitir: precisa verificar, com o emprego de metodologias e referenciais teóricos adequados, como esse jornalismo está sendo praticado e chamar atenção para que ele nunca se afaste da 
sua função de contribuir, através da informação qualificada, com a construção de uma vida sustentável, com paz e justiça socioambiental para todos.

\section{Referências}

ABREU, Mírian Santini de. 0 discurso jornalístico do desenvolvimento sustentável: uma interpretação sob o ponto de vista geográfico. 2004. Dissertação (Mestrado em Geografia) Universidade Federal de Santa Catarina, Florianópolis, 2004.

AGUIAR, Sonia. Apresentação da meta-análise sobre a Pesquisa em Comunicação Ambiental no Brasil (1988-2012). In: ENCONTRO INTERDISCIPLINAR DE COMUNICAÇÃO AMBIENTAL, 2 2013, Aracajú. Anais... Aracajú, 2013.

AGUIAR, Sonia. Comunicação Ambiental no Brasil: quem pesquisa? In: ENCONTRO NACIONAL DE PESQUISADORES EM JORNALISMO AMBIENTAL, 2., 2014, Porto Alegre. Anais... Porto Alegre, 2014.

BELMONTE, Roberto Villar. A construção do discurso da economia verde na revista Página 22. 2015. Dissertação (Mestrado em Comunicação e Informação) - Faculdade de Biblioteconomia e Comunicação, Universidade Federal do Rio Grande do Sul, Porto Alegre, 2015.

BRASIL. Presidência da República. Secretaria de Comunicação Social. Pesquisa brasileira de mídia 2015: hábitos de consumo de mídia pela população brasileira. Brasília, 2014.

BRASIL. Coordenação de Aperfeiçoamento de Pessoal de Nível Superior. Sobre o Banco de Teses: Histórico e evolução do Banco de Teses. c2006. Disponível em:

<http://bancodeteses.capes.gov.br/noticia/view/id/3>. Acesso em: 21 mai. 2015.

BUENO, Wilson. Comunicação, jornalismo e meio ambiente: teoria e pesquisa. São Paulo: Mojoara Editorial, 2007.

CAMPÊLLO, Lorena Oliveira de Souza. 0 meio ambiente em preto e branco: a mensagem ambiental nas páginas do jornal Gazeta de Sergipe (1972-1992). 2007. Dissertação (Mestrado em Desenvolvimento e Meio Ambiente) - Fundação Universidade Federal de Sergipe, São Cristóvão, Sergipe, 2007.

CAMPOS, Pedro Celso. Jornalismo ambiental e consumo sustentável: proposta de comunicação integrada para a educação permanente. 2006. Tese (Doutorado em Comunicação) - Universidade de São Paulo, São Paulo, 2006.

FERREIRA, Norma S. A. As pesquisas denominadas "estado da arte". Educação \& Sociedade, Campinas, v, 23, n. 79, p. 257-272, ago. 2002. Disponível em:

<http://www.scielo.br/pdf/es/v23n79/10857.pdf>. Acesso em: 5 mar. 2012.

GELÓS, Hernán Sorhuet. Periodismo Ambiental: eje comunicacional del siglo XXI. In: GIRARDI, Ilza; SCHWAAB, Reges (Org). Jornalismo Ambiental: desafios e reflexões. Porto Alegre: Dom Quixote, 2008. p. 67-74 
GERAQUE, Eduardo Augusto. Reportagens atravessadas: um mergulho via teoria geral dos sistemas na cobertura da poluição atmosférica feita por jornais brasileiros e mexicanos. 2006. Tese (Doutorado em Integração da América Latina) -Universidade de São Paulo, São Paulo, 2006.

GIRARDI, Ilza et al. Caminhos e descaminhos do jornalismo ambiental. Comunicação e Sociedade, São Bernardo do Campo, v. 34, n. 1, jul./dez. 2012. p. 131-152.

GIRARDI, Ilza Maria Tourinho et al. A pesquisa em Jornalismo Ambiental na região Sul do Brasil. In: Encontro Nacional de Pesquisadores de Jornalismo - SBPJor, 11, 2013, Brasília. Anais... Brasília: SBPJor, 2013a.

GIRARDI, Ilza Maria Tourinho et al. 0 olhar do jornalismo sobre a Economia Verde: estudo a partir da cobertura da Rio+20 pelos portais G1, UOL e Terra, Líbero (FACASPER), v. 16, p. 71-80, 2013b.

GOMES, Isaltina M. A. M. Do Grupo de Trabalho Comunicação e Ciência ao Núcleo de Pesquisa Comunicação Científica e Ambiental. In: Congresso Brasileiro da Comunicação da Sociedade Brasileira de Estudos Interdisciplinares da Comunicação (Intercom), 24, 2001, Campo Grande. Anais... Campo Grande: Intercom, 2001.

LIMA, Myrian D. V. et al. Jornalismo e meio ambiente: apontamentos sobre dez anos de produção acadêmica nos eventos da Intercom, Revista Intercom - Revista Brasileira de Ciências da Comunicação, n. 39, v. 2, 2015. No prelo.

LÜCKMAN, Ana Paula. Educação, jornalismo e meio ambiente: leituras sobre a crise ecológica no contexto do aquecimento global. 2007. Dissertação (Mestrado em Educação) Universidade Federal de Santa Catarina, Florianópolis, 2007.

MAFALDO, Norma Maria Meireles Macedo. Educação, Cultura e Jornalismo opinativo no suplemento JB Ecológico. 2008. Dissertação (Mestrado em Educação) - Universidade Federal da Paraíba, João Pessoa, 2008.

MASSIERER, Carine. 0 olhar jornalístico sobre o meio ambiente: um estudo das rotinas de produção nos jornais Zero Hora e Correio do Povo. 2007. Dissertação (Mestrado em Comunicação e Informação) - Universidade Federal do Rio Grande do Sul, Porto Alegre, 2007.

NOGUEIRA, Maria do Rosario Reis. Guia De Jornalismo Ambiental. 2008. Trabalho de Conclusão (Mestrado Profissionalizante em Biologia Urbana) - Centro Universitário Nilton Lins, Manaus, 2008.

RABELO, Desirré Cipriano. 0 Meio Ambiente de Mato Grosso do Sul na Mídia: análise das possibilidades educativas do jornal impresso. 1996. Dissertação (Mestrado em Educação) Fundação Universidade Federal de Mato Grosso do Sul, Campo Grande, 1996.

ROCHA, Mário Eugênio Villas-Bôas da. A comunicação da temática ambiental como expressão do pensamento complexo: um estudo exploratório no jornalismo gaúcho. 
2004. Dissertação (Mestrado em Comunicação Social) -Pontifícia Universidade Católica do Rio Grande do Sul, Porto Alegre, 2004.

TEIXEIRA, Dinair Veleda. A ética no discurso do jornal Zero Hora sobre as mudanças climáticas. 2008. Dissertação (Mestrado em Educação Ambiental) - Universidade Federal de Rio Grande, Rio Grande, 2008.

\title{
Overview of Environmental Journalism's Research in Brazil: the state of the art in dissertations and theses between 1987 and 2010
}

\begin{abstract}
This article presents an overview of studies on Environmental Journalism in Brazil through the mapping and analysis of theses and dissertations on the subject that are registered in the CAPES Bank of Theses in the period from 1987 to 2010. With a qualitative approach, a descriptive analysis of the abstracts of the studies was performed, with the goal of identifying subjects, theoretical-methodological background, empirical objects and the concept of Environmental Journalism; for the preparation of percentages and charts, we used quantitative analysis. The detailing of the 101 abstracts found allowed us to detect in what region there is a higher stimulus and interest in the area, the most used referential, the most recurrent gaps, among other aspects that characterize the state-of-the-art studies. Besides the contributions on what is Environmental Journalism and how is it being investigated in the country, we have verified that the definition of this expression is not clear not even among the researchers themselves.
\end{abstract}

\section{Keywords}

Environmental Journalism. Overview of research. State of the art.

Recebido em 11/09/2015

Aceito em 16/11/2015 